\title{
The Establishment of Cost Control System for Hainan Tourist Hotels
}

\author{
Chunchao Liu ${ }^{1}$, Huayou Duan ${ }^{2}$ \\ ${ }^{1}$ Hainan College of Vocation \& Technique, Haikou, Hainan, China, 570216 \\ ${ }^{2}$ Hainan Normal University, Haikou, Hainan, China, 571127
}

\begin{abstract}
Keywords: Hainan; Hotels; Cost Control
\end{abstract}
\begin{abstract}
Based on the study of the characteristics and composition of the hotel cost and the content and method of cost control in the hotel industry, this paper analyzes the relevant indexes of the cost control of Hainan tourism hotel in combination with the development level of Hainan hotel industry and the inherent law of cost control management Cost Control Department of Hainan Tourism Hotel.
\end{abstract}

\section{The Hotel Cost and Cost Control Theory}

The Concept of Hotel Costs. Hotel costs are broad and narrow sense of the narrow sense of the hotel cost refers to the cost of operations, that is, the hotel catering department, department and other business departments to ensure the normal operation and procurement of various materials costs and directly engaged in business staff salaries; generalized hotel costs include both operating costs, direct materials and direct labor, as well as various operating expenses such as water and electricity, coal and other energy costs, kitchen utensils, office supplies and other low-value consumables costs, cleaning, washing costs, Functional staff salaries, travel expenses and so on. The hotel usually refers to the cost of the cost of narrow, of course, different hotels to do the accounting, the cost of the definition is not the same.

The Main Content of the Hotel Cost Control. The human resource cost control. First of all, from the ideological to have full participation in the sense of cost control, establish a thrifty corporate culture; Secondly, from the system to adopt advanced human resources management concepts and systems, rational design of organizational structure, optimize the allocation of human resources, improve work Efficiency; Finally, the implementation of human management, attention to talent, retain talent, reduce staff turnover rate, which is an effective way to control labor costs.

The material cost control. Hotel operations cannot be separated from the material supplies, in its procurement, acceptance, storage and processing process will produce a variety of costs, it must be in every link to strengthen control

The energy cost control. The consumption of fuel gas, water and electricity is one of the major costs incurred during the operation of the hotel, especially the tourist hotels. In today's rising energy prices, energy saving is undoubtedly the most important thing to control the cost of the hotel.

The Method of Hotel Cost Control. Standard cost control method. In the use of this method, we must first develop a standard cost, that is, unit cost consumption quota, which is based on full consideration of cost forecasts, decision-making and planning and other information on the basis of scientific methods to investigate, analyze and calculate, by the cost manager developed in the ideal state of the enterprise should achieve a target cost.

The key to the method is to calculate the gross margin of each business sector, the gross margin of the business department $=$ gross margin of the business sector $\div$ income of the business sector $\times$ 
$100 \%$, the higher the gross margin, the better the cost control of the hotel, which is a traditional cost control method, by the hotel industry widely used.

The overall budget control law. As the name suggests, the key and basis of the method is to make a comprehensive budget, and its overall budget is the basis for cost control.

The main consumption control method. The method is to focus on the control of the cost of the cost of a significant impact on the consumption of indicators. The method is mainly used in hotel rooms and catering department, which focuses on human resources control and energy costs, catering department focused on human resources costs and material costs.

\section{The Relevant Indicators Analysis of the Hotel Cost Control}

The Cost Control Indicators of the Cost Level. This measure is calculated by dividing the cost of the amount by the amount of income used to calculate the proportion of the corresponding cost in the income, so as to measure the effect of the input on the resource input, which is roughly divided into the comprehensive cost rate and the individual Cost rate. The formula is: cost rate $=$ total cost cost $\div$ income $\times 100 \%$. By comparing the cost-to-income ratio with the industry level or the hotel plan, you can understand the level of cost and the level of profitability.

Analysis of Cost Quota and Cost of the Implementation of the Results of the Control Indicators. According to the hotel's historical level, the industry's advanced level and development goals to determine the amount of business consumption of materials standards and cost quotas, and accordingly determine the cost of the budget, in business, the business sector and financial cost control departments should be based on the actual consumption of materials and costs To be measured and compared with budget criteria and quotas. It mainly includes the following indicators.

" As the name suggests, is a room rental cost of the day, first calculate the room between the days of the cost, which includes the depreciation of the room, low-value consumables amortization, water and electricity costs, supplies costs, various service fees and labor and then calculate the room rental costs in the guest room according to the calculation formula $=$ the total cost of the room for the whole year / (the number of rental rooms $\times$ occupancy rate $\times 365$ days); Finally, the "days between rental costs" as the standard, The actual cost of comparative analysis, so as to achieve the purpose of cost control.

This indicator is through the space between the consumption of materials to carry out room cost control, but at the same time to be combined with the management system to carry out in the hotel cost control process, the consumption of supplies and budget quota or standard certainly have different, find out these the difference between the existence of the place and the reasons for the formation, you can do targeted, scientific control of the cost of materials; its formula is: days between the amount of material consumption $=$ calculated period of consumption of materials $/$ (number of rental rooms $\times$ calculated the number of days $\times$ occupancy rate).

Three is "hundred yuan turnover of fuel consumption." This indicator refers to the proportion of fuel consumption to operating income, which is calculated as follows: 100 yuan turnover fuel consumption $=$ calculated fuel consumption $/$ calculated total operating income $\times 100 \%$.

Fourth, "100 yuan turnover of the main business costs." This measure refers to the expenditure limit of the main business cost of the hundred yuan operating income. The formula is: hundred yuan turnover main business cost $=$ calculation period operating cost $/$ calculation period operating income $\times 100 \%$.

Analysis of Cost Performance and Breakeven Cost Control Index. From the cost of the hotel to decompose, all the cost of the project according to the cost and the relationship between the changes in business volume into the variable costs and fixed costs, and then according to different 
business estimates of its changes in the cost of the project and the ratio, the final consolidated business accounted for the proportion of total revenue Comprehensive change in the cost rate, so as to calculate the hotel revenue to complete the target and cost control objectives, by controlling the room changes in costs, control the cost of food changes to control the cost of change. Specific indicators include: comprehensive change in the cost rate, room rate of change, the rate of change in food and so on.

\section{The Establishment of Hainan Tourism Hotel Cost Control System}

The Steps and Methods of Establishment of the Hotel Cost Control System. The establishment of tourism hotel cost control system is a systematic engineering, scientific and rational design steps are to ensure its efficient and flexible premise, generally divided into the following five steps.

Determine the cost control objectives. The goal of cost control is the amount of revenue that should be obtained over a period of time and the amount of various costs. The criteria for setting goals should be based on a cost-controlled approach, such as the use of a comprehensive budget control method and a major consumption control method.

Calculate the actual operating results. The determination of the actual operating results must be strictly guaranteed. In the development of procedures, we should note the following points: First, the actual operation of the form of the results should be consistent with the standard form; Second, the actual business information collection should be simple and easy to operate; Third, the actual operating results of the calculation method to The method of calculating the standard is consistent; Fourth, the control index design must be consistent with the original vouchers of accounting; Fifth, the way to provide information must be consistent.

The actual operating results and standards for comparison. In the course of comparison, we should pay attention to the following points: First, often compare to make it become the daily work of managers; Second, we must compare the different periods; Third, to be timely comparison; Fourth, when the comparison, high Managers must be involved.

Analysis of the causes of the gap, put forward the solution. Managers not only to compare, but also to find gaps, analysis of the reasons for a major gap, and the development of appropriate response programs to be improved.

Use scientific methods to assess and give feedback. After the implementation of the improvement program, the effectiveness of the assessment through the assessment must be able to know, which requires managers to determine the appropriate assessment criteria, and the development of assessment procedures; and then, according to the procedures in a timely manner; in the assessment process to be realistic, objective fair, if found inappropriate procedures, but also timely adjustment to ensure the smooth progress of the assessment.

The Establishment of Hainan Tourism Hotel Cost Control System. Prior to the establishment of the hotel cost control system, first of all, should be collected in the history of the hotel the best level of cost data, to investigate the advanced level of the industry cost data, and comparative study. This article is mainly for the Ministry of Housing and Catering Department of the cost of the cost of control, and the scope of the cost of the hotel is divided into: human resources costs, material costs, energy costs, low value consumables and washing costs, engineering and maintenance costs, Management costs and taxes, etc., through the Hainan Province in 2015 five-star tourist hotel survey of the cost of investigation and analysis can be seen, for the Ministry of Housing, the cost of human resources and energy costs accounted for a higher proportion of cost, The average ratio of $20 \%$ and more than $45 \%$; for the catering department, the cost of human resources and material costs accounted for a higher proportion of the average ratio of $30 \%$ and $45 \%$, so the final key cost 
of this paper is: human resources costs , Material consumption costs and energy consumption costs, and calculate the Hainan Tourism Hotel corresponding to the average cost of human resources cost, the average cost of material and the average cost of return on energy costs

The establishment of food and beverage cost control system is a systematic project. First of all, the prerequisite for the implementation of cost control is to ensure that the hotel's product quantity and quality of service; Secondly, the establishment of food and beverage cost control system is a comprehensive budget control method, it should first determine the overall cost budget and budget indicators; The perfect cost control system should include at least three stages of feed forward control, process control and feedback control. To this end, I think it is necessary to establish a complete catering cost control system for Hainan hotel industry.

From the time series of guest housing, the cost of room costs are: depreciation expenses such as room and furniture, rents, utilities and other energy costs, low value consumables and washing costs, cleaning costs and salaries of service personnel, etc. The above costs can be calculated to get room costs.

\section{Acknowledgements}

Fund Project: Hainan Provincial Social Science Fund Project "Research on hotel cost control based on the sustainable development of "international tourism island" (project number HNSK (ZC) 16-6)

\section{References}

[1] Yin Junming, Wang Pingxin, etc. Evolutionary Logic of Cost Control Strategy: Based on Product Life Cycle [J]. Accounting Research, 2005 (3)

[2] Zhang Na. China's economy hotel cost control method [J]. Yanshan University, 2010

[3] Jia Ting. Based on the test period under the modern hotel catering cost control[J]. Xi'an University of Technology, 2010

[4] Meng Yue. Construction and management of food and beverage management cost control system .2012 (13) .P67-69

[5] Xu Lijing. On the overall budget and cost control. [J].Time Finance .2012 (5) .P94 